\title{
Association between ageing population, median age, life expectancy and mortality in coronavirus disease (COVID-19)
}

\author{
Xue-Qiang Wang ${ }^{1,2}$, Ge Song $^{1}$, Zheng Yang ${ }^{1}$, Ren-Jie Chen ${ }^{3}$, Yi-Li Zheng ${ }^{1}$, Hao-Yu Hu ${ }^{1}, X$ Xan Su ${ }^{1}$, \\ Pei-Jie Chen ${ }^{1}$ \\ ${ }^{1}$ Department of Sport Rehabilitation, Shanghai University of Sport, Shanghai, China \\ ${ }^{2}$ Department of Rehabilitation Medicine, Shanghai Shangti Orthopaedic Hospital, Shanghai, China \\ ${ }^{3}$ School of Public Health, Key Lab of Public Health Safety of the Ministry of Education and NHC Key Lab of Health \\ Technology Assessment, Fudan University, Shanghai, China
}

Correspondence to: Pei-Jie Chen, Xue-Qiang Wang; email: chenpeijie@sus.edu.cn, wangxueqiang@sus.edu.cn

Keywords: mortality, coronavirus disease, COVID-19, median age, life expectancy

Received: June 13, $2020 \quad$ Accepted: September 29, 2020 Published: November 24, 2020

Copyright: (C) 2020 Wang et al. This is an open access article distributed under the terms of the Creative Commons Attribution License (CC BY 3.0), which permits unrestricted use, distribution, and reproduction in any medium, provided the original author and source are credited.

\section{ABSTRACT}

As of May 5, 2020, the number of confirmed coronavirus disease (COVID-19) cases has been more than 3.5 million with 243,540 deaths. We aimed to determine the associations between ageing population, median age, life expectancy at birth and COVID-19 mortality. The numbers of COVID-19 cases and deaths in the European region were obtained from the World Health Organization database. The data on percentage of the population aged 65 and over, median age and life expectancy at birth were extracted from the World Factbook of Central Intelligence Agency. A total of 56 countries/areas in the Europe reported COVID-19 cases and deaths (1,121,853 cases and 100,938 deaths) on April 20, 2020. The results showed significant positive associations between COVID-19 mortality and ageing population ( $r=0.274 ; P=0.021)$, median age $(r=0.255 ; P=0.029)$, male median age $(r=0.284 ; P=0.017)$, female median age $(r=0.224 ; P=0.049)$, life expectancy at birth $(r=0.336 ; P=0.006)$, male life expectancy at birth $(r=0.342 ; P=0.005)$, female life expectancy at birth $(r=0.312 ; P=0.01)$ in the 56 European countries/areas. This study illustrated that COVID-19 mortality was positively associated with ageing population, median age, and life expectancy at birth.

\section{INTRODUCTION}

The World Health Organization (WHO) declared that the coronavirus disease (COVID-19) outbreak was characterized as a global pandemic on March 11, 2020 [1]. As of May 5, 2020, a total of 3,517,345 people infected with COVID-19 and 243,401 deaths in 215 countries/territories/areas were reported [2]. COVID-19 is still drastically spreading in the United States and Europe and the former had the greatest number of confirmed COVID-19 cases (61,906 deaths and $1,154,985$ cases). The case fatality rates in France, the United Kingdom and Italy reached as high as $15.08 \%$ (28,734 deaths and 190,588 confirmed cases), $13.54 \%$
(15,464 deaths and 114,221 confirmed cases) and $13.72 \%$ (29,079 deaths and 211,938 confirmed cases), respectively [2].

As reported in previous studies [3-10], age was an important factor for the case fatality rate of COVID-19 patients. In the United States [7], COVID-19 patients aged $\geq 85$ years $(10 \%$ to $27 \%)$ had the highest case fatality rate, followed by aged $65-84$ years $(3 \%$ to $11 \%)$ and aged $20-54$ years $(<1 \%)$. In Italy [11], the reported case fatality rates were $22.7 \%$ for those aged $\geq 90$ years, $19.7 \%$ for those aged $80-89$ years, $12.5 \%$ for those aged 70-79 years and 3.5\% for those aged 60-69 years. Furthermore, $\mathrm{Wu} \mathrm{C}$ et al. [8] found that the old age 
( $\geq 65$ years) was associated with a greater risk of developing death (hazard ratio 6.17, 95\% confidence interval 3.26-11.67). Similarly, another study [12] revealed that the old age ( $>70$ years) was significantly associated with the higher risk of death from COVID-19 (relative risk 10.67).

The case fatality rate of COVID-19 in Europe (9.29\%) was higher than that in the Americas (5.39\%), Western Pacific (4.09\%), Eastern Mediterranean (3.8\%), SouthEast Asia (3.69\%) and African $(3.41 \%)$ on May 5, 2020 [2]. Population age structure may explain the significant differences in case fatality rate across countries/territories/areas [13, 14]. In other words, the European region has the oldest populations among six WHO regions. The percentages of total population aged 65 years and over are estimated at $22.08 \%$ in Italy and $20.46 \%$ in France, compared with $16.85 \%$ in the United States and $12.34 \%$ in China [15]. In addition, the median ages are 46.5 years in Italy and 43.9 years in Spain, compared with 38.5 years in the United States and 38.4 years in China [15]. However, whether a relationship exists between population age structure and COVID-19 mortality in different countries/territories/areas remains unclear. Thus, this study was designed to determine the association between ageing population, median age, life expectancy at birth and COVID-19 mortality.

\section{RESULTS}

The characteristics of COVID-19 mortality, ageing population, median age and life expectancy at birth in 56 European countries/areas were summarized in Table 1. As of April 20, 2020, a total of 56 countries/areas reported 100,938 deaths and 1,121,853 cases of COVID-19 in the European region. The median values of ageing population, median age, male median age, female median age, life expectancy at birth, male life expectancy at birth and female life expectancy at birth were $18.61 \%, 41.76$ years, 40.15 years, 43.55 years, 80.2 years, 77.15 years and 82.85 years, respectively. The highest case fatality rate of COVID-19 came from France, at $17.43 \%$. The ageing population was from $5.8 \%$ in Kyrgyzstan to $35.15 \%$ in Monaco. The highest median age and life expectancy at birth were 55.4 and 89.3 years, respectively, in Monaco.

The results of Pearson correlation analysis between ageing population, median age, life expectancy and COVID-19 mortality were shown in Figures 1 and 2. The results showed significant positive associations between COVID-19 mortality and ageing population (Pearson correlation: $\mathrm{r}=0.274, \mathrm{P}=0.021$ ), median age (Pearson correlation: $\mathrm{r}=0.255, \mathrm{P}=0.029$ ), male median age (Pearson correlation: $\mathrm{r}=0.284, \mathrm{P}=0.017$ ), female median age (Pearson correlation: $\mathrm{r}=0.224, \mathrm{P}=0.049$ ), life expectancy at birth (Pearson correlation: $\mathrm{r}=0.336$, $\mathrm{P}=0.006$ ), male life expectancy at birth (Pearson correlation: $r=0.342, \mathrm{P}=0.005)$, female life expectancy at birth (Pearson correlation: $\mathrm{r}=0.312, \mathrm{P}=0.01$ ).

Regarding the ageing population in the 56 European countries/areas, COVID-19 mortality with $5.23 \%$ in the above median group was higher than $2.99 \%$ in the below median group $(\mathrm{P}=0.033)$ (Figure 3$)$. Regarding the median age, male median age and female median age, although the COVID-19 mortalities of the above median groups were slightly higher than the below median groups, there was no significant difference (median age, $\mathrm{P}=0.489$; male median age, $\mathrm{P}=0.186$; female median age, $\mathrm{P}=0.575$ ) (Figure 4). Regarding the life expectancy, male life expectancy and female life expectancy at birth, the COVID-19 mortalities of the above median groups were significantly higher than the below median groups $(\mathrm{P}<0.01)$ (Figure 4$)$.

\section{DISCUSSION}

We estimated the association between ageing population, median age (total, male and female), life expectancy at birth (total, male and female) in 2020 and COVID-19 mortality in 56 European countries/areas. The results showed COVID-19 mortality was significantly associated with ageing population, median age (total, male and female) and life expectancy at birth (total, male and female).

Our study confirmed that a country with a greater percentage of the population aged 65 and over had higher COVID-19 mortality rate. In 56 European countries/areas, the mortalities in France (mortality $17.43 \%$ and 110,721 confirmed cases), the United Kingdom (mortality 13.54\% and 114,221 confirmed cases) and Italy (mortality $13.23 \%$ and 175,925 confirmed cases) were higher than Turkey (mortality $2.3 \%$ and 82,329 confirmed cases) and Israel (mortality $1.21 \%$ and 13,107 confirmed cases) as of April 20, 2020. It could be explained by the reason that the percentages of the population aged 65 and over in France $(20.46 \%)$, the United Kingdom (18.48\%) and Italy (22.08\%) are significantly higher than Turkey $(8.35 \%)$ and Israel (11.96\%). Moreover, we found the similar results between the European region and other regions. For instance, the mortalities in France, the United Kingdom, and Italy were higher than Brazil (mortality $6.4 \%$ and 36,599 confirmed cases) and Mexico (mortality $8.67 \%$ and 7,497 confirmed cases) as of April 20, 2020. These findings were consistent with previous studies [3-10] that demonstrated the older age ( $\geq 65$ years) was a significant factor for the case fatality rate of COVID-19 patients. The main reason is that physiological disability with ageing, immune function 
Table 1. Dataset containing COVID-19 mortality, ageing population, median age, life expectancy in Europe region, as of April 20, 2020.

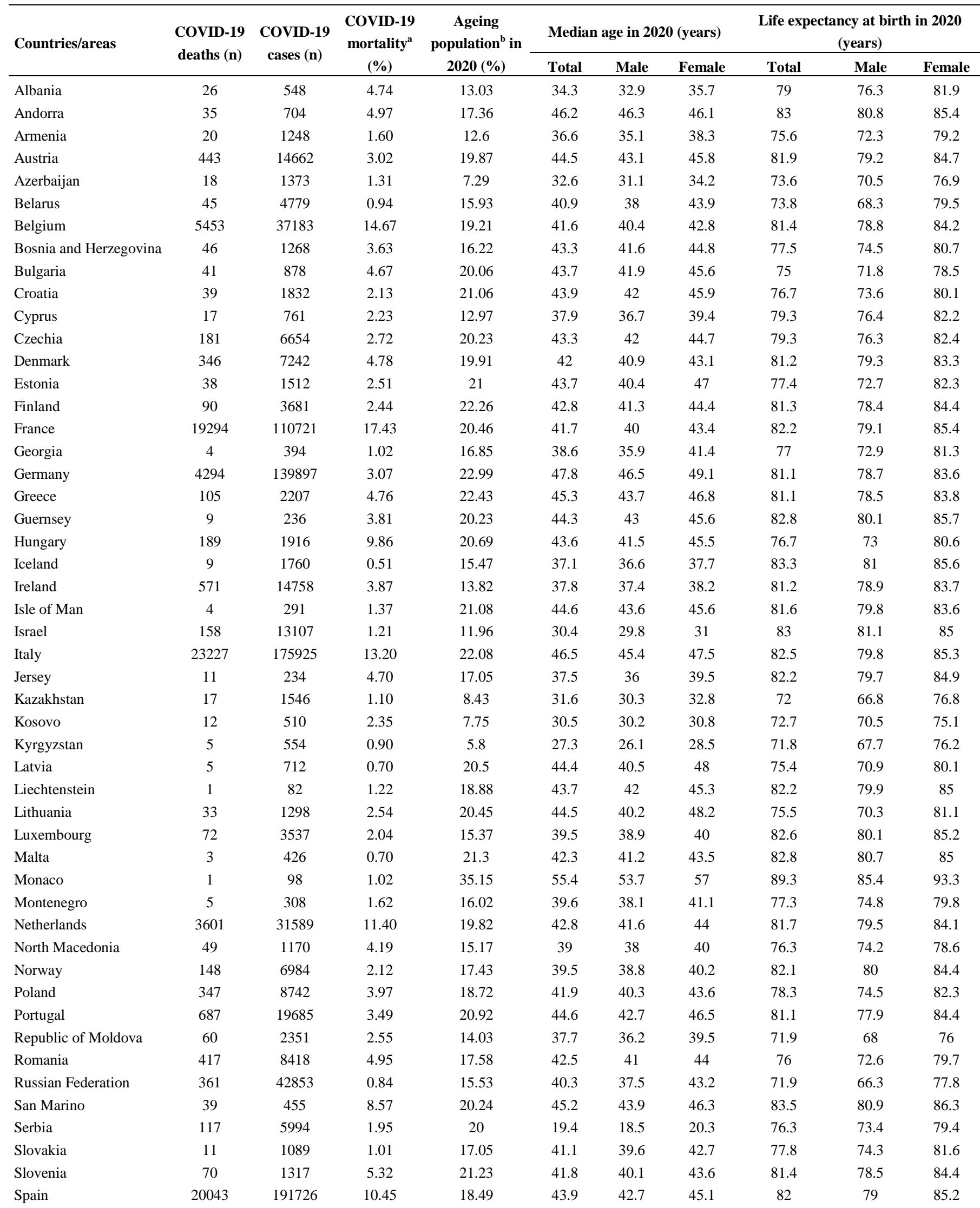




\begin{tabular}{lcccccccccc} 
Sweden & 1511 & 13822 & 10.93 & 20.59 & 41.1 & 40.1 & 42.1 & 82.4 & 80.4 & 84.5 \\
Switzerland & 1110 & 27322 & 4.06 & 18.73 & 42.7 & 41.7 & 43.7 & 82.8 & 80.5 & 85.3 \\
The United Kingdom & 15464 & 114221 & 13.54 & 18.48 & 40.6 & 39.6 & 41.7 & 81.1 & 78.8 & 83.5 \\
Turkey & 1890 & 82329 & 2.30 & 8.35 & 32.2 & 31.7 & 32.8 & 75.7 & 73.3 & 78.2 \\
Ukraine & 141 & 5449 & 2.59 & 17.03 & 41.2 & 38.2 & 44.3 & 72.9 & 68.2 & 77.9 \\
Uzbekistan & 5 & 1495 & 0.33 & 5.87 & 30.1 & 29.4 & 30.7 & 74.8 & 71.7 & 78 \\
\hline
\end{tabular}

Abbreviations: COVID-19, coronavirus disease.

a Mortality is case fatality rate of COVID-19, which is the number of confirmed deaths per the number of confirmed COVID-19 cases.

${ }^{\mathrm{b}}$ Ageing population is percentage of the population aged 65 and over in the total population.

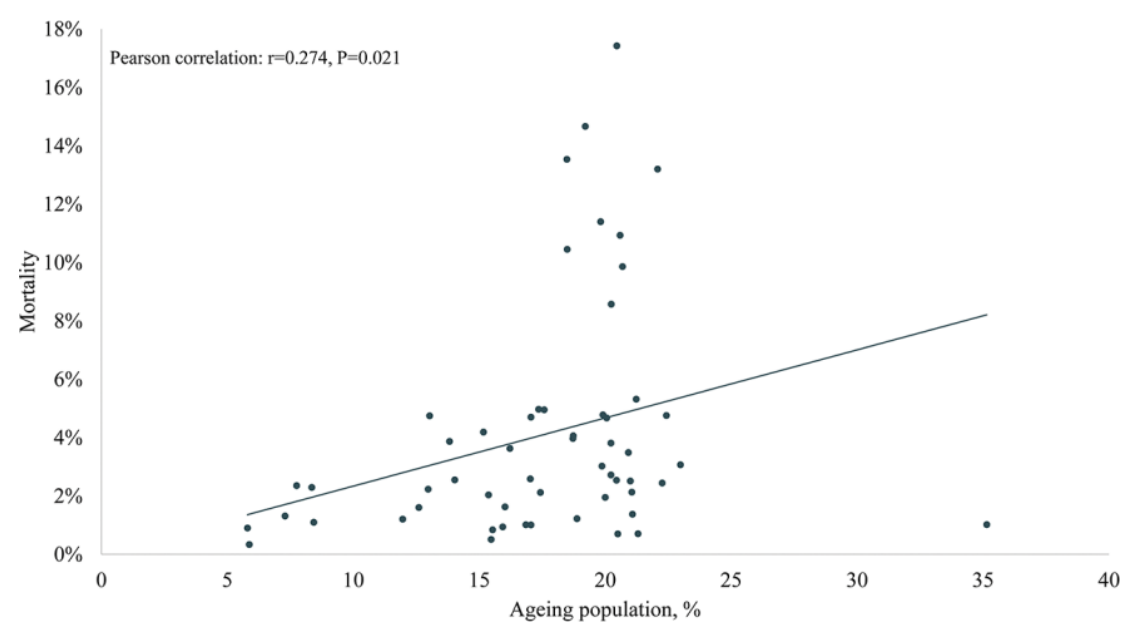

Figure 1. The association of ageing population in 2020 and COVID-19 mortality in Europe.
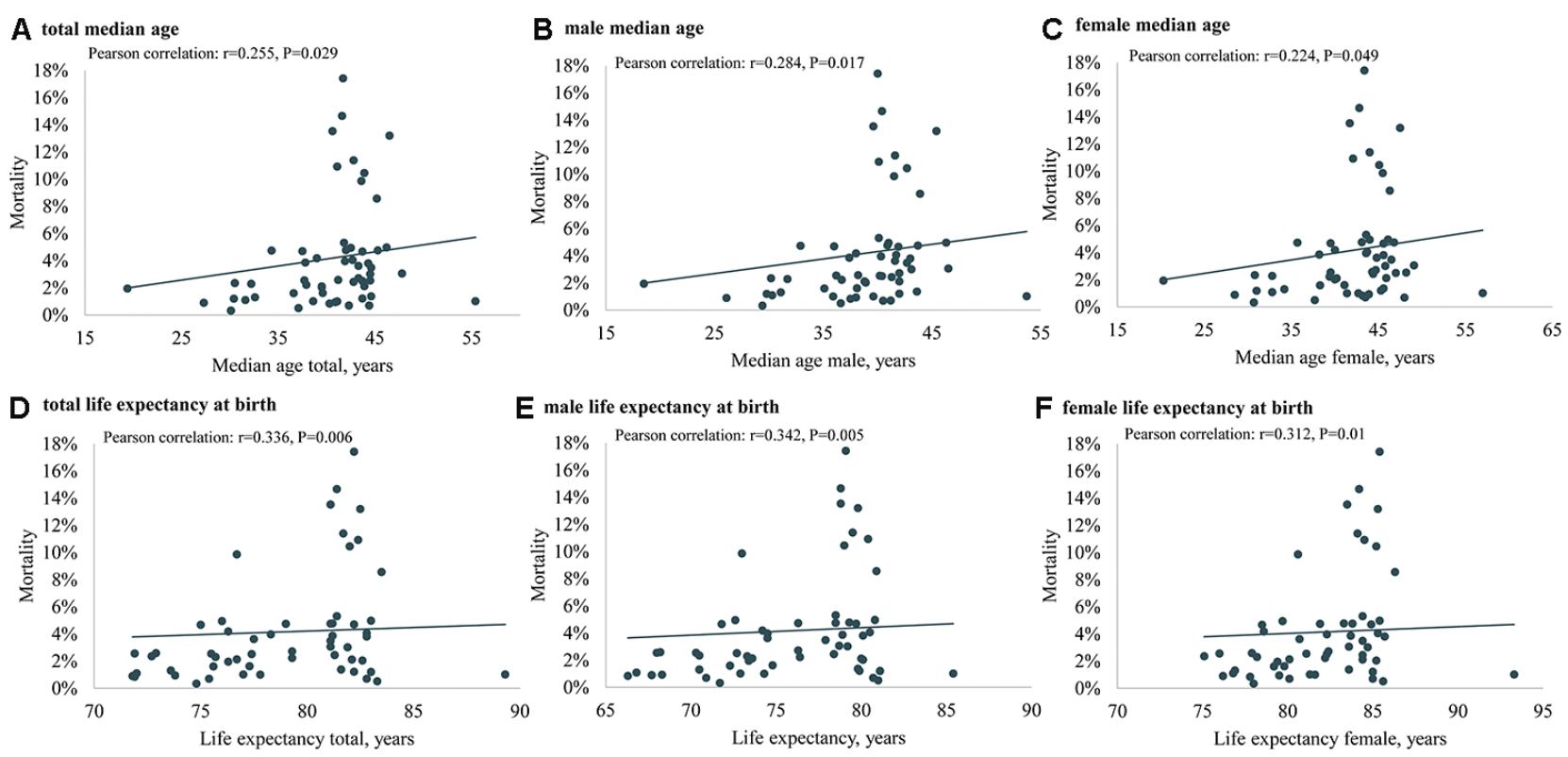

Figure 2. The association of median age (total, male and female) in 2020, life expectancy at birth (total, male and female) in 2020 and COVID-19 mortality in Europe. (A) total median age, (B) male median age, (C) female median age, (D) total life expectancy at birth, (E) male life expectancy at birth, (F) female life expectancy at birth. 
decline and multimorbidity in older adults may lead to serious complications or even death. Furthermore, the hyperfunction theory of quasi-programmed aging explains why COVID-19 vulnerability (mortality) is an agedependent syndrome and links it to other age-related diseases. Similarly, COVID-19 vulnerability (mortality) is associated with immunosenescence and cytokine storms as well [16]. Additionally, Dowd JB et al. [13] reported that diverse population age structure of different countries led to various mortality of COVID-19 around the world.

Furthermore, the case fatality rate of COVID-19 increased with median age across 56 countries/areas in this study. Chen $\mathrm{T}$ et al. [4] found that the median age of COVID-19 survivors (51 years) was significantly younger than that of non-survivors (68 years). Another study [8] reported that the median age of deceased COVID-19 cases (68.5 years) with acute respiratory distress syndrome was older than live patients (50 years). In this study, the COVID-19 mortality in Germany (mortality $3.07 \%$ and 139,897 confirmed cases) was obviously lower than Italy (mortality $13.23 \%, 175,925$ confirmed cases), which could be explained by the relative lower median age of COVID19 cases in Germany (48 years) and higher in Italy (64 years) $[11,13]$. Similarly, the COVID-19 mortalities in

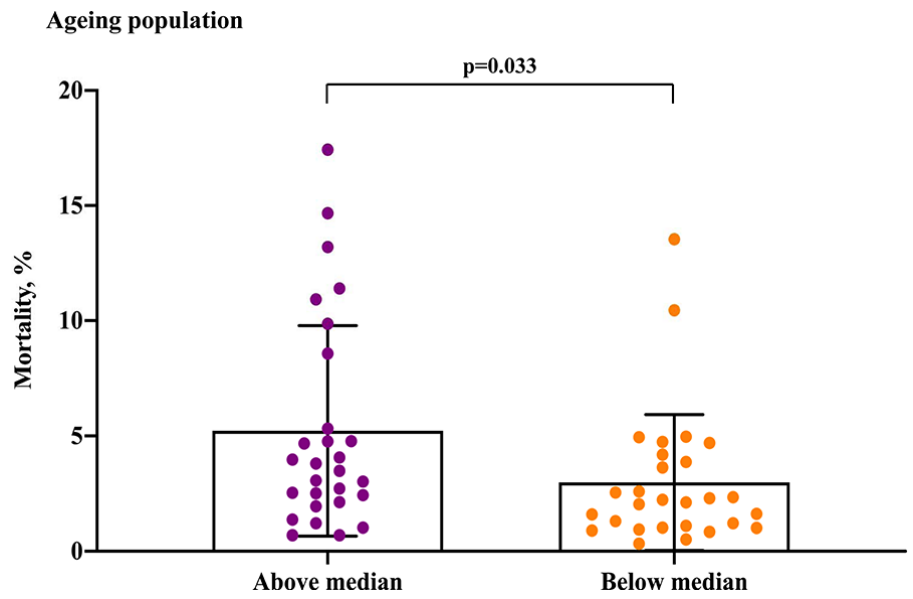

Figure 3. COVID-19 mortality for ageing population in the above median group versus the below median group.
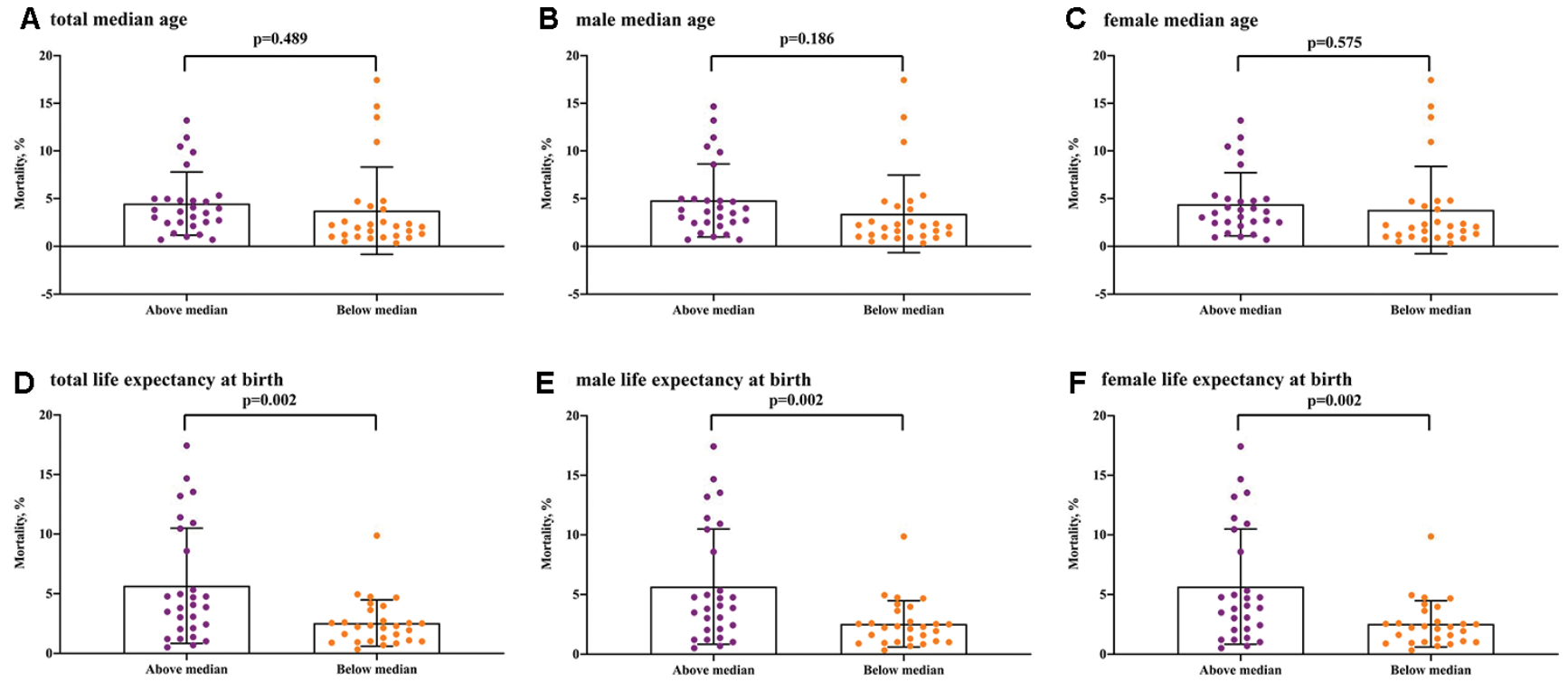

Figure 4. COVID-19 mortality for median age and life expectancy at birth in the above median group versus the below median group. (A) total median age, (B) male median age, (C) female median age, (D) total life expectancy at birth, (E) male life expectancy at birth, (F) female life expectancy at birth. 
France $(17.43 \%)$ and Italy (13.2\%) were higher than those in Israel (1.21\%) and Uzbekistan (0.33\%). The reason could be the median ages are 41.7 years in France and 46.5 years in Italy, compared with 30.4 years in Israel and 30.1 years in Uzbekistan. Meanwhile, there were the similar results between the European region and other regions. To illustrate, the COVID-19 mortalities of Span (10.45\%), and Netherlands (11.4\%) were higher than Argentina (mortality $4.65 \%$ and 2,839 confirmed cases) and Malaysia (mortality $1.65 \%$ and 5,389 confirmed cases) as of April 20, 2020. Correspondingly, the median ages are 43.9 years in Span and 41.6 years in Netherlands, compared with 32.4 years in Argentina and 29.2 years in Malaysia.

There were several major strengths in our study. First, to our knowledge, this work was the first to estimate the association between COVID-19 mortality with ageing population, median age, and life expectancy at birth in Europe. Second, since our study included 56 European countries/areas involving 100,938 deaths and 1,121,853 confirmed COVID-19 patients from the WHO databases, our results were reliably representative. Third, the subpopulation analyses (included total population, female and male) of median age and life expectancy at birth were conducted to further confirm the association between median age, life expectancy and COVID-19 mortality. These results further supported our hypothesis that COVID-19 mortality was positively correlated with median age and life expectancy at birth. Last but not least, our findings provided robust and novel evidence regarding the associations between ageing population and COVID-19 mortality in different countries/areas, which may explain the significant differences among COVID-19 mortality rates in the world.

This study had several limitations. First, although COVID-19 death was defined as "a death resulting from a clinically compatible illness in a probable or confirmed COVID-19 case, unless there is a clear alternative cause of death that cannot be related to COVID disease (e.g. trauma)" by the WHO [17], we could not eliminate the possibility of coding or diagnosis errors for death causes of COVID-19 in the 56 European countries/areas. In Italy, for example, a COVID-19 death is defined as a death occurring in a patient who has a positive laboratory-test result, while pre-existing diseases that may cause death are not considered [14]. Second, the ageing population, median age (total, male and female) and life expectancy at birth (total, male and female) of countries/areas in 2020 were provided and estimated by the World Factbook of Central Intelligence Agency [15]. Thus, this study may not be the true data of population age structure in the 56 European countries/areas. Third, despite our findings from Pearson correlation analyses that COVID-19 mortality was significantly associated with ageing population, median age and life expectancy at birth, COVID-19 mortality in a country/area was influenced by many factors, such as health-care workers, facilities, resources and public health policy for COVID19 [18-20]. To explain further, Germany and Italy had similar ageing populations $(22.99 \%$ for Germany and $22.08 \%$ for Italy), median age (47.8 years for Germany and 46.5 years for Italy) and life expectancy at birth (81.1 years for Germany and 82.5 years Italy) while significant differences existed in COVID-19 mortality between Germany (3.1\%) and Italy (13.2\%) as of April 20, 2020 [2]. This phenomenon could be caused by different public-health policy for COVID-19 (e.g., mandating isolation and banning gatherings), widespread testing for COVID-19 and healthcare resources (e.g., Germany had 29.2 critical care beds per 100,000 while Italy had 12.5) in Germany [21, 22]. We hoped that multiple linear regression analysis should be used to adjust for confounding factors. However, it was difficult for us to get the data, such as the number of health-care workers, physicians' density, hospital beds, hospital beds density, medical care costs and other medical facilities from 56 countries/areas in the European region.

This study provides several implications for policy and practice during the COVID 19 pandemic. First, the older age is an important factor for the case fatality rate of COVID-19 patients. Our results suggest that old adults should protect themselves to avoid being infected with COVID-19 and reduce chances of spreading. However, significant differences exist in some simple precautions, such as regular hand washing, keeping at least 1 meter distance from others, avoiding crowded places, avoiding non-essential travel [23-25]. Second, comorbidity is another key risk of death from COVID19. Therefore, elderly in comorbid conditions should be particularly vigilant and take protective measures to prevent COVID-19 infection. Old people with chronic diseases should maintain their medication supplies, take medications on time under the guidance of physicians and closely observe their symptoms of chronic diseases and disease progress. Third, growing numbers of older adults from 56 countries/areas in the European region and around the world are receiving care in long-term care facilities and nursing homes. Thus, all long-term care facilities and nursing homes should take protective measures to prevent the spread of COVID-19, including but not limited to restricting non-essential visitors, cancelling communal dining, monitoring fever and other symptoms of COVID-19 and providing necessary supplies (e.g. face mask) [26, 27]. Fourth, governments should provide additional financial supports, healthcare resources, public-health policy and support services for old adults during the COVID 19 pandemic. 


\section{CONCLUSIONS}

This study showed positive associations between COVID-19 mortality and ageing population, median age, and life expectancy at birth. Our findings can serve as a reference for old adults, medical staff, long-term care facilities and healthcare decision makers.

\section{MATERIALS AND METHODS}

\section{Study population}

This observational study was based on the WHO database on COVID-19 cases and deaths in European region as of 20 April 2020. All COVID-19 cases were confirmed through laboratory tests. A total of 56 countries/areas in the European region reported COVID-19 cases and deaths $(1,121,853$ cases and 100,938 deaths).

\section{Outcome measures}

We included the following outcome measures: case fatality rate of COVID-19, ageing population, median age (total, male and female) and life expectancy (total, male and female) at birth. The case fatality rate of COVID-19 is the number of confirmed deaths per number of confirmed COVID-19 cases. The ageing population is the percentage of population aged 65 and over in the total population. According to the United Nations, a region with an ageing population of over $7 \%$ is regarded as an aging society, $14 \%$ as an aged society, and $20 \%$ as a super aged society [28]. Median age is the age that equally separates a population into two groups (half the population are older than median age and half are younger), which is considered as a key single index for the age distribution of a population. Life expectancy at birth, the mean number of years that a newborn may expect to live, is a summary measure for the mortality and health of a population [29, 30].

\section{Data sources}

The numbers of COVID-19 cases and deaths in the European region were obtained from official situation reports issued by the WHO on April 20, 2020 [2]. We extracted the data on percentage of the population aged 65 and over, median age (total, male and female) and life expectancy (total, male and female) at birth in European countries/areas from the World Factbook of Central Intelligence Agency [15].

\section{Statistical analysis}

We used SPSS 22.0 software (SPSS, Inc, Chicago, USA) to conduct statistical analyses in this study. Categorical and continuous variables were presented as $\mathrm{n}(\%)$ and mean \pm standard deviation (SD), respectively. For the primary analysis, Pearson correlation coefficients was used to determine the association between ageing population, median age (total, male and female), life expectancy at birth (total, male and female) in 2020 and COVID-19 mortality in Europe.

In additional secondary analyses, a median split was performed to divide the outcome measures into two groups: above and below the median value. To explain further, 56 European countries/areas were equally separated into above and below median groups according to ageing population $($ median $=18.61 \%)$, median age $($ median $=41.76$ years $)$, median male age (median $=40.15$ years), median female age (median $=43.55$ years), life expectancy at birth (median $=80.2$ years), male life expectancy at birth (median $=77.15$ years) and female life expectancy at birth (median $=82.85$ years). We used independent sample $\mathrm{t}$ tests to analyse the significant difference in case fatality rate of COVID-19 between countries/areas above and below the median ageing population, median age and life expectancy at birth. Statistically significant differences would be determined with $\mathrm{P}$ values less than 0.05 .

\section{CONFLICTS OF INTEREST}

The authors declare that they have no conflict of interests. All authors have submitted the ICMJE Form for Disclosure of Potential Conflicts of Interest.

\section{AUTHOR CONTRIBUTIONS}

PJ. Chen and XQ. Wang designed the study. All authors whose names appear on the submission contributed substantially to the acquisition of data, or the analysis and interpretation of the data. XQ. Wang wrote the first draft of the manuscript, and all authors commented on previous versions of the manuscript. All authors read and approved the final manuscript.

\section{FUNDING}

This study was supported by the Shanghai Key Lab of Human Performance (Shanghai University of Sport) (11DZ2261100) and the scientific and technological research program of the Shanghai Science and Technology Committee (19080503100).

\section{REFERENCES}

1. World Health Organization. WHO Director-General's opening remarks at the media briefing on COVID-19 11 March 2020. 2020. https://www.who.int/directorgeneral/speeches/detail/who-director-general-sopening-remarks-at-the-media-briefing-on-covid-19--11-march-2020 
2. World Health Organization. Coronavirus disease (COVID2019) situation reports. 2020. (https://www.who. int/emergencies/diseases/novel-coronavirus-2019/ situation-reports.

3. Zhou F, Yu T, Du R, Fan G, Liu Y, Liu Z, Xiang J, Wang Y, Song B, Gu X, Guan L, Wei Y, Li H, et al. Clinical course and risk factors for mortality of adult inpatients with COVID-19 in Wuhan, China: a retrospective cohort study. Lancet. 2020; 395:1054-62.

https://doi.org/10.1016/S0140-6736(20)30566-3 PMID: $\underline{32171076}$

4. Chen $T$, Wu D, Chen H, Yan W, Yang D, Chen G, Ma K, Xu D, Yu H, Wang H, Wang T, Guo W, Chen J, et al. Clinical characteristics of 113 deceased patients with coronavirus disease 2019: retrospective study. BMJ. 2020; 368:m1091. https://doi.org/10.1136/bmj.m1091 PMID:32217556

5. Du RH, Liang LR, Yang CQ, Wang W, Cao TZ, Li M, Guo GY, Du J, Zheng CL, Zhu Q, Hu M, Li XY, Peng P, Shi HZ. Predictors of mortality for patients with COVID-19 pneumonia caused by SARS-CoV-2. Eur Respir J. 2020; $56: 2002961$.

https://doi.org/10.1183/13993003.02961-2020 PMID:32907886

6. Li X, Xu S, Yu M, Wang K, Tao Y, Zhou Y, Shi J, Zhou M, Wu B, Yang Z, Zhang C, Yue J, Zhang Z, et al. Risk factors for severity and mortality in adult COVID-19 inpatients in Wuhan. J Allergy Clin Immunol. 2020; 146:110-18. https://doi.org/10.1016/j.jaci.2020.04.006 PMID: 32294485

7. Bialek S, Boundy E, Bowen V, Chow N, Cohn A, Dowling $N$, Ellington $S$, Gierke R, Hall A, MacNeil J, Patel $P$, Peacock G, Pilishvili $\mathrm{T}$, et al, and CDC COVID-19 Response Team. Severe outcomes among patients with coronavirus disease 2019 (COVID-19) - United States, February 12-March 16, 2020. MMWR Morb Mortal Wkly Rep. 2020; 69:343-46.

https://doi.org/10.15585/mmwr.mm6912e2 PMID:32214079

8. Wu C, Chen X, Cai Y, Xia J, Zhou X, Xu S, Huang H, Zhang L, Zhou X, Du C, Zhang Y, Song J, Wang S, et al. Risk factors associated with acute respiratory distress syndrome and death in patients with coronavirus disease 2019 pneumonia in Wuhan, China. JAMA Intern Med. 2020; 180:934-43.

https://doi.org/10.1001/jamainternmed.2020.0994 PMID: $\underline{2167524}$

9. Nieman DC. Coronavirus disease-2019: A tocsin to our aging, unfit, corpulent, and immunodeficient society. J Sport Health Sci. 2020; 9:293-301. https://doi.org/10.1016/i.jshs.2020.05.001 PMID:32389882
10. Chen $R$, Liang $W$, Jiang $M$, Guan $W$, Zhan $C$, Wang $T$, Tang C, Sang L, Liu J, Ni Z, Hu Y, Liu L, Shan H, et al, and Medical Treatment Expert Group for COVID-19. Risk factors of fatal outcome in hospitalized subjects with coronavirus disease 2019 from a nationwide analysis in China. Chest. 2020; 158:97-105.

https://doi.org/10.1016/j.chest.2020.04.010 PMID: $\underline{32304772}$

11. Livingston E, Bucher K. Coronavirus Disease 2019 (COVID-19) in Italy. JAMA. 2020; 323:1335.

https://doi.org/10.1001/jama.2020.4344 PMID: $\underline{32181795}$

12. Fu L, Fei J, Xiang HX, Xiang $Y$, Tan $Z X$, Li MD, Liu FF, Liu $H Y$, Zheng L, Li Y, Zhao H, Xu DX. Influence factors of death risk among COVID-19 patients in Wuhan, China: a hospital-based case-cohort study. medRxiv. 2020. [Epub ahead of print]. https://doi.org/10.1101/2020.03.13.20035329

13. Dowd JB, Andriano L, Brazel DM, Rotondi V, Block P, Ding $X$, Liu $Y$, Mills MC. Demographic science aids in understanding the spread and fatality rates of COVID19. Proc Natl Acad Sci USA. 2020; 117:9696-98. https://doi.org/10.1073/pnas.2004911117 PMID: $\underline{32300018}$

14. Onder G, Rezza G, Brusaferro S. Case-fatality rate and characteristics of patients dying in relation to COVID19 in Italy. JAMA. 2020; 323:1775-76.

https://doi.org/10.1001/jama.2020.4683 PMID:32203977

15. Central Intelligence Agency. The World Factbook. 2020. (https://www.cia.gov/library/publications/ resources/the-world-factbook/.

16. Blagosklonny MV. From causes of aging to death from COVID-19. Aging (Albany NY). 2020; 12:10004-21. https://doi.org/10.18632/aging.103493 PMID:32534452

17. World Health Organization. International guidelines for certification and classification (coding) of COVID-19 as cause of death. 2020. https://www.who.int/ classifications/icd/Guidelines Cause of Death COVID19.pdf?ua=1

18. Rajgor DD, Lee MH, Archuleta S, Bagdasarian N, Quek SC. The many estimates of the COVID-19 case fatality rate. Lancet Infect Dis. 2020; 20:776-77. https://doi.org/10.1016/S1473-3099(20)30244-9 PMID: $\underline{2224313}$

19. Adams JG, Walls RM. Supporting the health care workforce during the COVID-19 global epidemic. JAMA. 2020; 323:1439-40. https://doi.org/10.1001/jama.2020.3972 PMID:32163102 
20. Cohen IG, Crespo AM, White DB. Potential legal liability for withdrawing or withholding ventilators during COVID-19: assessing the risks and identifying needed reforms. JAMA. 2020; 323:1901-02.

https://doi.org/10.1001/jama.2020.5442

PMID:32236491

21. Stafford N. Covid-19: why Germany's case fatality rate seems so low. BMJ. 2020; 369:m1395. https://doi.org/10.1136/bmj.m1395 PMID:32265194

22. Rhodes A, Ferdinande P, Flaatten $H$, Guidet B, Metnitz PG, Moreno RP. The variability of critical care bed numbers in Europe. Intensive Care Med. 2012; 38:1647-53.

https://doi.org/10.1007/s00134-012-2627-8

PMID:22777516

23. Montero-Odasso M, Goens SD, Kamkar N, Lam R, Madden K, Molnar F, Speechley M, Stranges S. Canadian geriatrics society COVID-19 recommendations for older adults. What do older adults need to know? Can Geriatr J. 2020; 23:149-51. https://doi.org/10.5770/cgj.23.443 PMID:32269670

24. Morley JE, Vellas B. Editorial: COVID-19 and older adults. J Nutr Health Aging. 2020; 24:364-65. https://doi.org/10.1007/s12603-020-1349-9 PMID:32242202

25. Shahid Z, Kalayanamitra R, McClafferty B, Kepko D, Ramgobin D, Patel R, Aggarwal CS, Vunnam R, Sahu N, Bhatt D, Jones K, Golamari R, Jain R. COVID-19 and older adults: what we know. J Am Geriatr Soc. 2020; 68:926-29. https://doi.org/10.1111/jgs.16472 PMID:32255507

26. Davidson PM, Szanton SL. Nursing homes and COVID19: we can and should do better. J Clin Nurs. 2020; 29:2758-59. https://doi.org/10.1111/jocn.15297

PMID:32281165

27. Kimball A, Hatfield KM, Arons $M$, James A, Taylor J, Spicer K, Bardossy AC, Oakley LP, Tanwar S, Chisty Z, Bell JM, Methner M, Harney J, et al, and Public Health - Seattle \& King County, and CDC COVID-19 Investigation Team. Asymptomatic and presymptomatic SARS-CoV-2 infections in residents of a long-term care skilled nursing facility - King County, Washington, March 2020. MMWR Morb Mortal Wkly Rep. 2020; 69:377-81.

https://doi.org/10.15585/mmwr.mm6913e1

PMID:32240128

28. Koohsari MJ, Nakaya T, Oka K. Activity-friendly built environments in a super-aged society, Japan: current challenges and toward a research agenda. Int J Environ Res Public Health. 2018; 15:2054.

https://doi.org/10.3390/ijerph15092054

PMID:30235862

29. Chen H, Chen G, Zheng X, Guo Y. Contribution of specific diseases and injuries to changes in health adjusted life expectancy in 187 countries from 1990 to 2013: retrospective observational study. BMJ. 2019; 364:1969.

https://doi.org/10.1136/bmj.1969

PMID:30917970

30. Woolf SH, Schoomaker H. Life expectancy and mortality rates in the United States, 1959-2017. JAMA. 2019; 322:1996-2016. https://doi.org/10.1001/jama.2019.16932 PMID:31769830 